\title{
How to Penetrate Humanistic Thought in College English Teaching
}

\author{
Lin Yan \\ College of Foreign Languages, Wuhan Donghu University, Wuhan, 430212, China
}

Keywords: College English teaching, Humanistic thought, Humanistic quality, Penetrate, Strategy

\begin{abstract}
In order to better promote the comprehensive development of students' comprehensive quality and enhance the humanities, into Humanism in College English teaching is very necessary. Since college English teaching contains a lot of humanist thought, so in teaching activities in how to effectively penetrate humanist thought, the humanities students with a certain strategy and methods, become the most important problem to be solved. This review focuses on college English teaching how to penetrate Humanism in the analysis of the actual situation, a reasonable response measures in order to better promote the development of education in Chinese universities.
\end{abstract}

\section{Introduction}

With the pace of new curriculum standards of education reform in depth, corresponding to College English Teaching put forward higher requirements, higher education not only need to take responsibility for the spread of knowledge, but also need to develop students' good moral character, humanities, establish the correct values, thus facing serious challenges. Due to the rapid development of market economy, the corresponding desire for comprehensive talent degree increase as college enrollment coupled with the implementation of the policy, resulting in a sharp increase in the number of college students, humanistic ideas generally low level of education, there are a small number of university students and even ignore life, maiming and psychological changes of life, indirectly reflected that the lack of ideological education. College English Teaching contains a lot of humanistic ideas of factors, subtle penetration humanistic ideas of students, helping students to a more profound understanding of humanistic ideas, the formation of a good cultural ideology, comprehensive quality development.

\section{Overview of humanistic thought}

Humanistic ideas originally born in the era of the European Renaissance, with its humanist essence there was no significant difference when humanistic ideas originally born, mainly to promote people-oriented, against God exalted status in people's minds, emphasizing people's own values; theological objections ascetic philosophy, advocating people brave pursuit of freedom of life, promote people are born free and equal, live in harmony with nature, nature can promote human development made outstanding contributions. Develop humanistic ideas to modern society, absorbing the more modern elements, including personal thought, freedom of thought and the idea of people-oriented. People-oriented, is the first time in the "government" theory, is the promotion of human supremacy, everything should be in order to artificially measure, the core of social development is human [1]. The idea is that individuals personal rights are the most important, far higher than other social rights; individual right to life and property should be respected. Freedom of thought refers to personal freedom, the government should find ways to trample on citizens' personal freedom, a person only with humanistic ideas, is a person of sound thinking, recognize their own position in social development, will not make there loss of lives and property of others things, for the social development and make greater contribution to become a happy man. 


\section{Significance of college English teaching penetrating humanistic thought}

\section{Problems exist in college English teaching}

With the global economic integration approaching footsteps, English as an international common language, the role has become even more prominent, English teaching has become the main focus of foreign language teaching in colleges and universities; it has an important role [2]. College English Teaching on the status of view, the overall effectiveness of low current, too much emphasis on universities CET English assessment, whether teachers or students for examination by paying a great deal of effort to put more energy into the English evaluation, Over time, causing teachers and students learning English and Professor of boredom breed. Progress and development of society, compared to the past, either psychologically or college students own knowledge structure, are more mature, showing individual characteristics. Similarly, the problem faced by college students in English learning process has become even more serious, such as support or lack of motivation to learn too strong motivation to learn, learn many problems tired, memory disorders, seriously restricting the college English teaching activities carried out smoothly [3].

In addition, because of the current Chinese universities and teaching methods of English teaching environment is lagging behind, teaching methods used adaptability is weak, widely used in various disciplines teaching, that teaching effectiveness is low, become the main reason for school learning efficiency [4 ]. Therefore, in the current era background, higher education reform should radically change the traditional teaching ideas, the introduction of new teaching methods, purposeful, conscious of the teaching content with real-life linked, combined with students' individual learning needs and solve new problems, become One of the first to explore the topic of current academia.

The introduction of new teaching method in college English teaching, including teaching methodology compromise, 3T teaching method, etc., as well as many domestic scholars teacher summed up the work carried out in practice in a more innovative English teaching methods, teaching strategies and more to promoting English curriculum reform, teaching methods based on innovation. In the government vigorously promote people-oriented concept under the guidance of college English teachers should be actively involved, for college English teaching bold attempt, the humanist ideas into teaching activities, deepening the college English teaching activities [5].

\section{Possibilities humanistic thought instructing college English teaching}

Pay attention to the comprehensive development of humanistic ideas, the pursuit of the development of the human personality, is not a specific thing, but an act of wisdom. Humanistic ideas have outstanding educational characteristics, its most prominent feature is the naturalness and subjectivity for the college English teaching permeate humanistic ideas suggests a greater possibility and practice space. In addition, humanistic ideas through continuous development and development, the development so far, which covers a large number of outstanding East-West cultural characteristics, on the one hand reflects the morality of shape, on the other hand gives it new meaning. Education characteristics Humanities students focus on personality development, against asceticism, release the student's nature, through education to reshape personal character, encourage students to physical and mental health.

\section{Significance of college English teaching penetrating humanistic thought}

College English teaching activities, and should fully clear the current educational requirements, in order to cultivate students 'comprehensive quality as the main goal, to enhance students' English proficiency. English instructional design a broader range, including many students learning ability and memory word, analytical reading and oral communication ability, thus requiring teachers in English teaching activities, it should improve the English teaching model innovation degree of attention, training students' English comprehensive ability, in order to better adapt to modern social needs. Based on this, innovative English teaching mode needs to mobilize the enthusiasm of students, wholeheartedly involved, contact the real-life English effectively enhance the comprehensive ability to develop good identify problems, analyze problems and problem-solving skills. But for years to 
College English Teaching in view, serious lack of humanistic ideas, resulting in English teaching theory with practice out of touch, despite the higher student test scores, but far less than the practical application, pending further innovation and improvement, seek more as a reasonable solution to enhance students' English comprehensive ability.

\section{Strategy of humanistic thought penetrating in college English teaching}

\section{Penetration of humanistic thought needs to be balanced}

College English teaching activities during the main task remains to impart knowledge of English, exercise, and enhance students' English ability based. Seen in this light, human thinking is not the main task of teaching college English, using penetration way to promote humanistic ideas into them, so humanistic ideas become major college English teaching content, teaching uphold the original intention. English teachers in the humanities infiltrate the idea of the process, need to grasp the sense of propriety, naturally to students about humanistic ideas, encourage college students unknowingly been influenced by ideology, in order to avoid the infiltration permeate away. When humanistic ideas permeate, teachers should always pay attention to the feelings of the students, in order to avoid student learning humanistic ideas bored, teachers should pay attention to avoid a torrent of truths in life education, and then the classroom into the ideological and political education to those who preach identity to carry out teaching activities. This will result in the student conflict, tired of psychology, resulting in learning English from the original track. Thus, in order to mobilize the interest of students should create a variety of humanistic ideas learning atmosphere, combined with students' psychological characteristics, we targeted a reasonable choice of teaching methods for students to create a good cultural atmosphere of attention to education. For example, in English, "Life in the future" the teaching process, if a simple guide students to carry articles in English learning, will cause students to fatigue in learning English, tired of learning English, therefore, in the "Life in the future" a text teaching can be appropriate to introduce some humanistic ideas interspersed content, which gradually penetrate, guide students to think, "Life, what new things we will encounter in the future?" "Life, humanism and what kind of world the essence of humanism future change difference "in the background of this teaching, college English classroom to help create a good learning environment, and fully mobilize the enthusiasm of students to participate. In addition, the process of learning English, the humanistic ideas penetrate into English teaching, students play the initiative, and students deepen their understanding of the knowledge and mastery of English in a relaxed, cheerful learning environment to help improve English teaching efficiency.

\section{Guide students to feel culture contained in English}

Contained in different languages of different cultural backgrounds, the area affected by human factors, the language of culture to a certain extent, reveal the cultural identity of the nation, so there are significant differences between ethnic cultures of different languages, English primarily reflect national cultural identity in the English-speaking, compared to the same point there are some characteristics of Chinese culture inherent in, but more is different. From this, in college English teaching teachers should give full play to its role in guiding, to introduce students to the cultural background of the language, prompting students to perceive depth inherent in English language and culture, to deepen understanding of language, seeking between English with Chinese differences, to enhance students' language and culture perception, in respect of foreign languages at the same time, strengthen their understanding of the language, giving students more tolerant of humanistic ideas. College English teaching activities in English textbooks most articles are in English-speaking countries cultural background as the basis, teachers can about the content of the article at the same time, interspersed with the English national cultural background information. Such as, "Christmas" is the English text of the more famous, well known article about the teachers in this article, it can be appropriate to talk about some details about Christmas, which countries in the West have had Christmas, Christmas will do What things, etc., led the students further insights East-West cultural differences. At the same time, teachers can create the Christmas situation for students, so that students 
can further perceive the implied humanistic ideas. In addition, some English spoken introduction can help students understand more intuitive speech habits of the East and West, to help communicate with foreigners more convenient. Such as the British meet to talk mainly weather for the beginning of the conversation can be habit teachers tell students when and Englishman should first talk to the weather as the starting point, to ensure smooth conversation with a foreigner.

\section{Reinforce students' humanity aesthetic consciousness}

Aesthetic sense is an integral part of humanistic thought, and who has a certain aesthetic ability to be able to discover the subtle little things in life in the United States, perceive and appreciate beauty. Therefore, we should pay attention to Students' aesthetic sense, to a certain extent, affect the future quality of life of students. College English Teaching there are many beautiful places, such as in the English word pronunciation and composition, teachers can take students aesthetic consciousness, in acquire more knowledge of English at the same time, enhance the aesthetic perception.

Furthermore, it should focus on the creation of human thought permeate teaching mode, teaching of English in the integration of current humanistic ideas, and guide students to actively participate in the learning activities, to deepen understanding of the extent of thinking on English culture, improve their English learning efficiency. Such as, in the English text "Healthy eating", teachers can ask a series of questions, to mobilize the enthusiasm of students to participate, our food culture inherent in the humanistic thought of "what are the problems in our health foods?", "' Let the students into groups to discuss, combined with the reality of the social and human thought, more in-depth knowledge of the English exploration and learning.

\section{Conclusions}

In summary, the university is to cultivate talents education base, college students as an important guarantee for the development of China's future prosperity, so professional quality level of the student population will directly affect China's overall national strength, and look at the status quo in recent years to Quality Education of College Students look, the overall effect is low, humanistic ideas declining quality of university students, which greatly reduces the personnel training quality. For such problems, universities should fully recognize the importance of English in the teaching of Humanities, for a reasonable penetration strategy, and continuously enrich the connotation of humanistic thinking, encourage students’ comprehensive quality development.

\section{References}

[1] Wang Yi. Research and Application of humanist philosophy in College English Teaching. Journal of Tonghua Normal College 2013(05):71-73.

[2] Sun Lin. Feasibility analysis on integrating modern humanist education into college English teaching. Jiannan Literature (Classic teachers' house),2013(07):362-363.

[3] Yang Xiaochun. Recalling of foreign language teaching method and humanistic thought in 20th century and its revelation for college English teaching reform. Journal of Nanjing University of Science and Technology(social sciences edition),2012(04):59-64.

[4] Long Chunfang. Attempt of humanity penetration in college English teaching. Journal of Changsha Railway University(social sciences edition),2011(04):127-128.

[5] Meng Zhiming. Humanistic thought penetration in the process of college English and American literature. Journal of Kiamusze Vocational School,2014,37(08):78-79. 